\title{
Mucin-Producing Adenocarcinoma
}

National Cancer Institute

\section{Source}

National Cancer Institute. Mucin-Producing Adenocarcinoma. NCI Thesaurus. Code C27379.

An invasive adenocarcinoma composed of malignant glandular cells which produce mucin. 